\title{
THEORETICAL AND METHODOLOGICAL ISSUES OF THE RESEARCH OF MODERN TRANSFORMATIONAL PROCESSES OF UKRAINIAN SOCIETY
}

\section{Dunayeva L. M.}

\section{INTRODUCTION}

The whole process of transformation of Ukrainian society after independence should be subordinated to the sole goal of building a sovereign and independent, democratic, social, constitutional state and civil society based on market economy and strong social policy. This goal stemmed from the objective needs of the civilized development of our country at the turn of the century. The objective needs of social progress, combined with the goal-aspiration of our people for national independence and well-being, should be transformed into the grand tasks of state building on the basis of democratic principles, transformation of the socialist economy into a market and national revival.

However, modern social development is characterized by crisis phenomena in the functioning of all countries of the world. Globalization processes have led to significant consequences in all spheres of society. Particularly complex processes covered post-socialist countries, that faced with problems of qualitative changes in the system of social institutions and the interconnections between them. The search for a new model of the functioning and development of society for this group of countries is also compounded by the crisis phenomena in social sciences, due to the lack of a clear paradigm, and even more so, a theory that would contain answers to these problems.

Complex and contradictory processes of transformation of modern Ukrainian society cause the need for theoretical and methodological principles, on the basis of which theoretical approaches and concrete social projects of qualitative updating of the system of social institutes of our country are developed. Throughout its history, humanity has created a number of diverse social practices, models of social development, which, in the process of scientific reflection, were presented in relevant scientific theories and paradigms. The task of Ukrainian scientists is to master the world experience of the theory and 
practice of social changes, scientific knowledge about them, and develop an adequate model of social development, which should take into account the historical, political and legal, national-cultural and mental features of contemporary Ukrainian society.

The main thesis of all theoretical studies and methodologies is the impossibility of describing the new social reality characterized by globalization processes, the dissemination of informational technologies and others by means of old methods. The question of the methodology of modern research is a constantly debated topic, since each scientific research must be based on the appropriate methodology of scientific analysis. Modernity testifies not only to the crisis of the search for a paradigm, the crisis of social reality, but about the crisis of science in general.

The present state of the evolution of social science and development of theoretical and methodological foundations have become the subject of research by Western scholars such as I. Wallerstein, D. Bel, Y. A. Toynbee, E. Toffler, S. Huntingon and others. Questions of theoretical and methodological nature were the subject of analysis by such Ukrainian scientists as L. Bevzenko, A. Halchinsky, V. Gorbatenko, G. Pocheptsov, V. Semynozhenko, S. Vovkanych and others.

An analysis of the works of Western scholars became the subject of a special study by A. Galchinsky, who offers to use the theory of complex and non-equilibrium systems as a methodology of new social studies, the author of which is considered by well-known social scientist I. Prigozhin. The methodology of these systems is based on the systematic approach that appears as the basis for this study.

\section{Formation and development of theoretical and methodological approaches to the transformation of modern Ukrainian society}

For modern Ukraine implementation of a model of sustainable and accelerated development requires systemic changes, a set of concrete socio-economic, political, ideological, socio-cultural measures aimed at the formation of qualitatively new, integrated and organic system of society. This set of measures should be based on the study and creative application of historical experience of developed countries of the modern world, which is largely reflected in modern theories of social development. The diversity of these theories has led to the need of systematizing them according to certain criteria within the framework of 
the corresponding paradigms. These criteria are the methodological principles that are inherent in a close group of theories, which is covered by a certain paradigm. It is within the framework of paradigms that Ukrainian researchers carry out an analysis and search for specific theoretical and methodological foundations of a vital model of the development of our society.

Ukrainian researcher S.Vovkanych writes that «for Ukraine, the theory of sustainable development at any level (country or region, nation or individual) will only function effectively when it comprehensively covers the whole range of strategic priorities, including the factors of state formation and nationalization ${ }^{1}$. Such an approach may be defined as an offer of a paradigmatic approach to the system of social transformations of modern Ukrainian society. The subject of such a paradigm should be not only the classical issues of economic, social and state-legal system, but also the question of the spiritual and intellectual unity of the Ukrainian nation, its consolidation, affirmation and development of political, ethnic, cultural, and religious identity.

However, the success of solving these problems in the conditions of globalization of the modern world depends at a large extent on the introduction of a new socio-humanistic paradigm into the sphere of international relations, the moral and ideological principles of which would be based on the entire complex of factors, which, in addition to the socio-economic and political aspects mentioned, would have taken into account spiritual-intellectual, informational-linguistic, demographic, ethnic and other dimensions, without which social stability and sustainable development are impossible.

In the developed countries of the modern world, there is the so-called integration strategy of development, which tries to fit all of these criteria. It refers to «a set of methods of managing society for targeting its actions, actions in a certain socio-economic, political, environmental areas» ${ }^{2}$ The socio-human component of this management strategy is seen as a paradigmatic binary, the essence of which is the parity approach to harmonizing the combination of rights and protection of both person and nation in the widest range of contexts, as well as in terms of the prompt

${ }^{1}$ Vovkanych S.Y. Socio-humanistic paradigm of integration strategy of Ukraine and its regions. Regional economy. 2008. No. 3. P. 7-22.

${ }^{2}$ Ibid. 
delivery of this moral and legal imperative to international jurisdiction to this socio-humanistic binarism. Such a global interpretation of the format of the strategy involves systemic consideration as the structure of its essential components, and the directions of their functional content and practical implementation. This, in turn, means that the human-nationalstate-centeredness of the community must be determined in the internal dimension, mainly focused on integration around the implementation of the Ukrainian national idea, information space, solution of socioeconomic, national-democratic, administrative-territorial and other problems of the country, in particular, interregional and interindustrial, as well as in the external, international - focused on cooperation or other interactions of Ukrainian society with the world community, with neighbors, in particular their attitude towards the restoration of Ukraine, its spiritual revival and the preservation of the identity of the nation, the choice of the vector and strategic partners on the way to the peaks of world civilization development.

Introduction of such a paradigm in contemporary scientific research raises questions about the relevance of the old methodology of research to new realities, new paradigms. In this regard, more and more scientists in the field of social sciences believe that modern science is in a state of crisis, based on its methodological principles. This is primarily about the need to overcome the principle of "linearity", which expresses the methodological basis of the analysis of social processes. These scholars argue that every historical date, every civilization implies its own model of knowledge, a specific method of studying the connection between theoretical concepts and substantiated conclusions about the real world and its perspectives. It is a fact that during the periods of steep turns in history, theoretical constructions, concepts and laws relating to previous development, their methodological structure, in particular, the method of study, are obsolete and do not correspond to new social realities.

It is necessary to pay close attention to the fundamental warnings concerning the crisis of social sciences. This is said for a long time since the 70's of the last century. This problem became especially acute nowadays when the crisis of science coincided with the crisis of social reality. The modern world undergoes significant changes, and science, being conservative in its essence, does not keep up with these changes. This leads to a significant uncertainty in the social future. 
In general, social sciences do not stand still. A considerable amount of actual material on globalization and national transformations has been worked out. However, it is not a quantitative measure of accumulated knowledge. The crisis in social sciences is the lack of progress in the methodological basis of analysis. The lack of generalizations at the level of the methodology expresses the essence of the problem, which is fully relevant to the latest theoretical generalizations - the theory of postindustrial society. These are the works of D. Bell, O. Toffler, M. Kasteselsva and other scholars, whose works formulate modern scientific ideas about the principles of post-industrialism, which are based on the orthodox methodological principles of traditional modernism. This is their fundamental scientific limitations. They refer to the substantiation of the prerequisites for the approval of the basic principles adequate to the conditions of the transition phase, rather than the basic characteristics of the new post-industrial society, which have not yet fully evaporated.

Thus, in D. Bell's main features of industrial, industrial and postindustrial society are distinguished on the basis of one-line (linear) logic, based mainly on quantitative changes that characterize the sectoral structure of production, distribution of labor, and so on. On the same traditional methodological basis, the specific features of post-industrial society are substantiated by many other scientists. Nowadays, this is an acknowledged fact that determines the fundamental limitations of relevant research. The need for the formation of a new methodological paradigm is primarily due to the fact that the accumulated stratum of scientific concepts of the modern post-industrial era is formed on the old methodological basis of the previous era, on the principles of industrialism, modernist logic.

In the context of the restructuring of the methodology of research on the development of contemporary Ukrainian society, the key issue is to rethink the complex of scientific postulates associated with the concept of causality. This is the problem of the existing frame of causal determinants, which are based on the methodological postulates of Newtonian physics, and in many of its aspects lose their relevance to modern social transformations: to explain the logic of the latter based on the established causal causation clauses becomes impossible.

From the point of view of the logic of global transformations, the most controversial position of this methodology is the absolutization of the principles of technical (technological) and economic determinism, 
according to which technological and economic factors are considered as the driving force of social progress.

Criticism of this doctrine has different aspects. First of all, it takes into account the discrepancy of its frames with real historical processes. In particular, it cannot explain the reasons behind the western technological miracle.

Analyzing the laws of development of civilizations known in the world, we suppose that the degree of domination of society over nature is determined by the level of technical progress, but we observe cases where technical development was accelerated, and civilization remained static.

As an alternative to the aforementioned methodological frame, spiritual values are offered. M. Weber affirmed that the basis of society's development is not technology, not material, but spiritual life, religion, sphere of consciousness as a whole.

Another interpretation of the problem posed is presented by D. Nort, who gives priority to the development of the economy to institutional changes, and first of all to unofficial institutional constraints (customs, traditions, codes of conduct, etc.). "It's impossible to understand history without recognizing the leading role played by subjective preferences in the context of official institutional constraints" ${ }^{3}$.

E. Shills offers another frame, he advocates the principle of political determinism as determinant in the system of society. "The main factors that create and preserve society are central government, consent and territorial integrity"4. In such position there is a rational component. The transition from pre-industrial to industrial society is accompanied by the collapse of the system of traditional forms of social regulation, the state of social "anomie", while new mechanisms of regulation and regulation of social relations are only being drawn up. In these circumstances, the power-political factor, forming the system of legislative, executive and judicial power, plays an important role, the whole process of social transformations, and often fate of the country itself, depends upon the action and interaction of which.

Ukrainian scientist A. Ablov believes that the defining principle of social determination is historic. In the industrial society there is economic

${ }^{3}$ Nort D. Institutions, institutional change and functioning of the economy. Kyiv: Gaydariki, 2000. 385 p.

${ }^{4}$ Shills E. Society and Societies: Macrosociological Approach. American Sociology. Prospects, problems, methods. Moscow: Progress, 1972. 392 p. 
determinism, in the industrial - political, and in post-industrial - cultural determinism. At the same time, in his opinion, the industrial society is a transitional stage from pre-industrial to postindustrial society, the effectiveness of which depends primarily on power and politics. So according to A. Ablov: "The strategy of social change should be based on knowledge of the laws and forms of functioning and development of social relations, their interactions and determinations in specific historical conditions and interrelationships of the past, present and future. If the traditional society was characterized by economic determinism of the interactions of social relations and spheres of life, then the socio-cultural factor in the post-industrial stage is becoming increasingly dominant. In fact, industrial society serves as a transitional phase to the post-industrial stage. The transition from the traditional to the industrial stage was characterized by the destruction of social order, the emergence of a state of social anomie, revolutionary social changes, and the establishment of political determinism in the system of interactions of social relations" ${ }^{5}$. The leading countries of European civilization passed the transitional stage of the industrial society in about two centuries, while the "Asian tigers", the countries of Southeast Asia for several decades.

Thus, the attitude of M. Weber, A. Toynbee, N., E. Schilz, A. Ablov in principle does not breach the methodology and logic of determinism, the principles of modernism.

Attempting to overcome this methodological contradiction makes O. Toffler, while emphasizing that the methodology of modernism continues to be useful, but it should be used only for the analysis of individual, simple in its content changes - as a methodology of simple systems.

The logic of causality of the systemic connections of the Third Wave Society is substantiated by O. Toffler on methodological principles that are close to the I.Prigozhin methodology. A.Galchinsky in this methodology considers it expedient to define such features: "... firstly, it is an understanding of causality as a system of complex (multi-vector) interaction of diverse in its nature forces; secondly, it is a need to identify not only direct but also opposite, positive and negative links; thirdly, it is an explanation of complex phenomena and processes based on a

${ }^{5}$ Ablov A.F. Some Problems of the Theory and Practice of the Transformation of Modern Ukrainian society. Herald of the Odessa National University. Series: Psychology. Vol. 23. Issue 2 (48). 2018. Odessa: "Astroprint". p. 7-22. 
combination of random and necessary; and fourthly, this is the assumption of self-exciting processes". ${ }^{6}$

Thus, the new methodology opens the way for the development of methodological construction, which is not in the mechanical denial of one another, but in their logical continuity, mutual enrichment.

Perspective in terms of overcoming existing methodological constraints can be considered a relatively new direction of research, which was called postmodernism, or concepts of "the postmodern modernity".

Of course, today it is impossible to speak of postmodernism as an already formed, relatively holistic theory. "It is too early to say that postmodernism is the basis of this methodology, but its antithesis to the logic of modern modernism, it is evident from the need for a careful attitude towards its basic postulates ${ }^{7}$.

Methodological contradictions between the principles of modernism and postmodernism relate primarily to the basic problems of determining the phenomenon of the present. It is about finding answers to questions about which phenomena of social life and its characteristics carry the essential features of a new society and which of them can be interpreted as obsolete social forms inherited from the previous stage and in the long term must be overcome. It is precisely postmodernism that focuses on the global divide between dying and asserted forms of society.

Most of the differences between the methodologies of modernism and postmodernism can be reduced to two aspects - rationality of human activities and problems of equilibrium and self-regulation of social processes.

Modernism focuses on the rationalism of human activity, on the material interests of individuals, while postmodernism pays more attention to the increasing role of moral-psychological, ethical factors of human activity in the modern world.

Regarding the equilibrium problem, modernism is based on the postulate in which society evolves to equilibrium, which is realized in an automatic mode, is based on the rationality of human activity, as well as on the principle of historicism: systemic transformations are realized on the trajectory - from non-equilibrium to equilibrium in the future, from

${ }^{6}$ Galchinsky A. Global transformations: conceptual alternatives. Methodological alternatives. Methodological Aspects: [Science Edition]. Kyiv: Lybid, 2006. 312 p.

${ }^{7}$ Ibid. 
equilibrium of the first order - to a more balanced equilibrium of the second order and so on.

In today's social realities, which have signs of deep system transformations, the principle of non-equilibrium development begins to dominate. The bifurcation point is a position in which the systemic equilibrium is denied. Therefore, equilibrium should be considered not as a universal constant, but as a specific situation, which: a) is always limited in space and time; b) is responsible only for simple systems; c) is considered as a separate case.

It is important to consider another methodological caveat. Modernism is organically linked with industrialism, capitalism, and the national and state organization of society, whereas postmodernism denies these basic postulates of the corresponding methodology, opposing to them the theory of complex non-equilibrium processes, the fundamental principles of which were formulated by representatives of natural sciences and mathematics.

Postmodernism focuses on the assertion of the individual, the subjective factors in social development. In the conditions of the preindustrial and industrial epochs, real life was a society, not an individual. In contrast to such an installation, according to the new methodology, a separate human person acquires the status of a reality capable of selfrealization and being known by itself. In the framework of this scientific direction, a methodological individualism is formed that focuses the attention of scientists on humanistic values, the self-realization of man, its dominant meaning in the system of society.

Much of the leading scientists in the field of social sciences see the overcoming of the scientific crisis in the constructive synthesis of theoretical studies of the entire spectrum of social sciences. "We learned in the process of theoretical analysis to dismember the problems of social development into constituents, and this in its time was a fundamental asset of scientific research. Nowadays the main task of social science is to assemble separate parts into a whole, to form the principles of generalizing theory, theory, more adequate logic of modern transformations" 8 .

${ }^{8}$ Galchinsky A. Global transformations: conceptual alternatives. Methodological alternatives. Methodological Aspects: [Science Edition]. Kyiv: Lybid, 2006. 312 p. 
Such formulation of the question has several arguments. It is, on the one hand, about the fundamental complications of the systemic connections of social processes and the difficulty of their holistic comprehension, which the modern methodology encountered, on the other hand - the impossibility of mastering without such an understanding the logic of individual processes that are only known as part of the whole, and not as segregated segments.

The essence of the problem of scientific synthesis concerns not just interdisciplinary cooperation, but a higher level of cooperation - mutual enrichment at the methodological level, the formation of the systemic integrity of cognitive process on the basis of the logic of methodological monism with emphasis on sociologization and humanization of all sciences.

\section{System approach as a necessary condition for the formation of methodological foundations for the transformation of modern Ukrainian society}

Despite the existing variety of theories and their methodological foundations, the method of systematic approach remains the basis of scientific methodology, which at the same time serves as a way of logical thinking, system perception and appropriate information ordering. Systemicity is also an integral part of the management of complex objects.

System analysis is based on the law of complex (integral) systems, according to which the whole is greater than the sum of its parts. A holistic complex system differs from the summation (simple) formation of subordinate systemic links between constituent elements and assertions of systemic quality. In this case, the system principles of functioning and development become the dominant ones. Such a system is self-sufficient, working on the basis of its own (system) laws, requirements of which are subject to its structural components.

However, it is essential to keep in mind that in the system integrity, their own qualitative values of the constituent structures do not completely disappear. Subordinating to the whole, they at the same time maintain their relativity. Power system, the contradictions of its development is formed on the basis of the corresponding interaction.

It is important to understand that these definitions are not abstract; they are easily projected onto real social processes and can be used as methodological principles of cognition. An example of this is the process 
of forming the structural integrity of the global system. It is well known that the history of human civilization is marked by the unity and interdependence of development. Mankind has always been the only one. And this union took place even when relations between nations and peoples on their external features did not only failed to receive a clear manifestation, but also were antagonistically contradictory, developed in accordance with the principles of a simple system dominated by horizontal between segments (interstate) ties.

The fundamental novelty of the modern stage lies in the fact that civilization is developing in the direction of gradual overgrowth of the simple integrity of the world into a structural one. It is an extremely complex contradictory process, which in many aspects has not yet become consistent. The methodology of system analysis creates a sufficient basis for their scientific reflection.

The methodology of system analysis proceeds from the three-phase development of each functioning system:

- genesis, when the system is in the phase of summation (simple) integrity;

- maturity when the system becomes a structural integrity;

- a decline that occurs at a time when potential of the development of the system itself is exhausted.

Contradictions of development are changing into contradictions of decline, which cannot be overcome. This leads to the bifurcation of the system, its replacement by one or several new systems, which, on the one hand, are antipodes of their predecessors, develop on the basis of immanent (opposing) principles and laws, on the other - they are more complex in their structural construction.

Schematically, the development of the system can be presented in the form of the following steps: a) the formation of integral quality of the system; b) change of the properties of the structural components of the system, their subordination to the system integrity; c) formation of new integral structures, on the basis of which the functional qualities of the approved system are implemented.

Thus, the methodology of system analysis proceeds from the fact that each system is not only historical - it has its beginning and the end, develops within a certain space and its own historical time, and is based on the principles of self-development. The logic of historicism is the logic of historical self-development - development, which is ensured through 
the implementation of the internal energy potential of the system. For this study, this thesis is a starting point, since it allows one to combine the branches of public authority, power and self-government, defining the latter as the energy potential of the power system in society.

Ukrainian scientist A.Galchinsky indicates that the potential of selfdevelopment is formed on the basis of three types of contradictions. First, the contradictions between the whole and the individual structural elements of the system. Whole acts as a determinant of their parts, converts them according to their nature. The energy potential of the development of the system is formed primarily on this basis.

Secondly, the energy of development is growing not only on the basis of subordinate links between the whole and parts, but also on the basis of interaction between individual parts or groups of parts. It is said that, subjecting to the whole, separate structural elements in the stages of formation and development of the system actively counteract each other.

Thirdly, the energy of the system's development is generated from the external environment. The sign of the system is its relative closeness and limitations to the outside world. . This is a fundamentally important position. Only in the process of interaction with the external environment the system reveals its properties, its certainty, which do not allow it to dissolve in the environment, function and develop relatively independently 9 .

Thus, sources of accumulation of the energy potential of the system are its heterogeneity and contradiction. Systems remain meaningful only when the whole and system, the structural links of the system, and, finally, the system and the external environment are differentiated when heterogeneous integration of the system takes place, when the principle of hybrid enrichment is realized, on the basis of which system quality and energy potential of the system grows. . In a situation where a systemic integrity is achieved, when the relevant links become homogeneous, when the system acquires signs of homogeneity, its energy potential begins to decay. It becomes mutant, nonviable, vulnerable to external influences, loses the potential of self-preservation. Finally, the system, which achieves the relative homogeneity and structural identity of its components, decays; its differentiation, dismemberment occurs.

${ }^{9}$ See Galchinsky A. Global transformations: conceptual alternatives. Methodological alternatives. Methodological Aspects: [Science Edition]. Kyiv: Lybid, 2006. 312 p. 
In general, the system is considered to be life-sustaining when the energy of its internal connections (vertical and horizontal) exceeds the energy impact of the external environment. If the internal potential of self-development becomes less than the total energy of external influences, the integrity is destroyed from the outside and eventually collapses.

In this context, the methodology of system analysis delimits the functional laws - the laws of self-realization of the system within the limits of the available certainty, its essential quality and laws of development, which determines the mechanisms of qualitative transformations of the system, processes not only its formation and development, but also decline and disappearance.

Correspondingly, there are different types of contradictions contradictions in the development and contradictions of the collapse. Controversial development associated with the adaptive capabilities of the system; contradictions of the decay fulfill the opposite function. They lead to the death of the system, moreover, in the historical aspect, they are inevitable. The principle of historicism of the system is based on this inevitability.

However, new accents are now being set up, increasingly turning to the impossibility of new ideological foundations, a new culture of thinking. No one denies the importance of system analysis, but all state the appropriateness of reviewing systemic research. At least five positions in the new approach to systemic methodology are actualized at the present stage of development of social sciences, namely:

1) complex systems are primarily dynamic systems;

2) complex systems belong to a class of orderly systems;

3) according to the principles of functional complexity, it is precisely the transient systems that represent only one of the chains of the evolutionary process, a peculiar "prehistory" of the new, which only arises and is established. They are implemented through the mechanisms of bifurcation and chaos. The state of the bifurcation is identified with a deviation from the standard cause-and-effect determinism and equilibrium. The dominant development is an accident. Under chaos, this state of the system is understood; its memory in relation to the previous linearly deterministic state is completely lost. And the state of bifurcation 
and chaos as a state of disorder, according to I.Prigozhin, is a payment for the possibility of establishing a new order ${ }^{10}$;

4) the notion of complex is organically correlated with the specifics of the so-called dissipative systems, which exclude the possibility of reverse development, are based on the principles of the irreversibility of processes;

5) description of complex systems requires not deterministic, but probabilistic approach.

Modern society is an extremely complex system, consisting of many subsystems of different levels and complexity. The study of modern social processes requires the development of methodological foundations of theories, scientific paradigms, the application of a systematic approach, in which various theoretical and methodological concepts appropriate to the social nature of reality, which is the direct subject of the study, must be used. The system methodology and other approaches based on it should become the methodological basis for enriching theoretical researches of social processes, determining the place and role of numerical subsystems in modern Ukrainian society and their transformation in accordance with the needs of social progress.

When developing a new strategy, it is necessary to take into account the existing contradictions between classical science, education and modern innovation trends that can be overcome only by preserving the best traditions along with the systematic implementation of the latest technologies into the social practice of transforming modern Ukrainian society.

\section{CONCLUSIONS}

Describing the state of theoretical and methodological principles of scientific research of the transformational processes of contemporary Ukrainian society, it should be noted:

1) the growth of pluralism and the presence of numerous competing theories and paradigms of social development, each of which, depending on the specific conditions, may become a priority;

2) in the analysis of social processes, it is necessary to take into account not only the general strengthening of subjective factors associated with changes in the place of man in the social structure of

\footnotetext{
${ }^{10}$ Prigogin I., Stengers I. Time. Chaos. Quantum. Moscow: Nauka, 1998. 438 p.
} 
modern society, but also the modification of human nature, the growth of the range of its freedom and individuality, overcoming alienation;

3 ) the theory of complex non-equilibrium systems does not narrow in any way, but on the contrary - expands the prospects of scientific research, including political ones. These are the principles of denying the predictability of the future as a product of self-development. The future cannot be a pre-planned process. One can only express hypotheses regarding the development paths based on the use of quantitative data. However, the normative function of social sciences is not to construct the future reality, but to find out how it is formed, and at the same time, comparing social structures, to promote a more rational reality. However, it should be understood that such justifications will always be not only relative, but also those that have exclusive application in well-defined systems;

4) in modern science, the most important methods of scientific research are revised, in particular the principle of scientific abstraction and the principle of combining logical and historical approaches in the study of social processes. Questioned the correctness of the widely used in modern research tools of analysis of the logic of ascending development, the movement from the simplest elementary forms to mature systems. It is believed that any characteristics of the simplest form of the social process in the best case explain the past and in any case not modern;

5) at the present moment in the social sciences the question arises of the essential reorganization of the existing mechanisms and methods of scientific knowledge. The methodology itself undergoes significant changes. Old methodological canons no longer work, and new ones do not work yet - they are not systematically formed. Principal challenges to the modern scientific process give rise to crisis phenomena in the field of scientific research. The problems of science are reflected in the social practice of the transformation of modern Ukrainian society.

\section{SUMMARY}

The paper deals with theoretical and methodological approaches to the study of the transformational processes of modern Ukrainian society. The author analyzed the existing social theories and scientific paradigms in which the search for the most adequate methodological principles of transformational social changes aimed at sustainable and accelerated 
development corresponding to the features of the post-industrial stage of society was carried out in world and Ukrainian scientific activities. It is argued that the peculiarity of modern social development is its crisis situation, the uncertainty of the future and, at the same time, the crisis of social sciences, their theoretical and methodological principles. All this complicates the resolution of the problems of qualitative transformations in post-communist countries, Ukraine in particular. Further studies of the transformational processes of modern Ukrainian society, as argued by the author, should be based on the systematic approach methodology.

\section{REFERENCES}

1. Vovkanich S.Y. Socio-humanistic paradigm of the integration strategy of Ukraine and its regions. Regional economy. 2008. No. 3. P. 7-22.

2. Nort D. Institutions, Institutional Change and Functioning of the economy. Kyiv: Gaydariki, 2000. 385 p.

3. Shills E. Society and Society: Macrosociological Approach. American Sociology. Prospects, problems, methods. Moscow: Progress, 1972. $392 \mathrm{p}$.

4. Ablov A.F. Some problems of the theory and practice of transformation of modern Ukrainian society. Herald of the Odessa National University. Series: Psychology. Vol. 23. Issue 2 (48). 2018. Odessa: "Astroprint". p. 7-22.

5. Galchinsky A. Global transformations: conceptual alternatives. Methodological Aspects: [Science Edition]. Kyiv: Lybid, 2006. 312 p.

6. Prigogin I., Stengers I. Time. Chaos. Quantum. Moscow: Nauka, 1998. $438 \mathrm{p}$.

Information about the author: Dunayeva L. M. Doctor of Political Science, Professor, Odesa National I. I. Mechnikov University 15/13, Tenistaya str., Odesa, 65009, Ukraine 